\title{
A study on homogenization methods for steels with varying content of ferrite, bainite and martensite
}

\author{
Stefan Golling ${ }^{\mathrm{a}, *}$, Rickard Östlund ${ }^{\mathrm{a}}$, Mats Oldenburg ${ }^{\mathrm{a}}$ \\ ${ }^{a}$ Division of Mechanics of Solid Materials, LuleåUniversity of Technology, SE-97187 Luleå, \\ Sweden
}

\begin{abstract}
The demand of ultra high strength steel (UHSS) components increased in the last decade due to their high strength to weight ratio. The driving force in this development is the automotive industry and regulations concerning passenger safety and fuel consumption. The use of ultra high strength steel enables design of lighter car bodies with equal or better passenger safety compared to earlier car generations. The automotive industry and their suppliers need predictive tools in the development of components with tailored material properties. Components with tailored material properties are produced by hot stamping, in this process a blank is austenitized before it is formed and quenched in one step. By use of sequential heated or cooled tools, different mechanical properties distributed within the same component are achieved.

In order to develop a constitutive model for components consisting of regions with varying phase content, a suitable method to describe the elasto-plastic part of the yield curve is needed. The focus of this work is on the description of the elasto-plastic constitutive model of an ultra high strength steel depending on the phase content in the material. Different volume fractions of ferrite, bainite and martensite are experimentally formed. In this study the capability of different homogenization methods on the prediction of the material response of a multiphase steel depending on the volume fraction of formed phases is investigated. The modeling results are compared to experimental results.

The prediction of the composite response using the micromechanical based double-inclusion model and pure phase measured data as well as experimentally obtained phase volume fractions of present phases showed good agreement throughout all samples tested in this study.
\end{abstract}

Keywords: Microstructure, Homogenization, Hot stamping

\footnotetext{
* Corresponding author

Email address: stefan.golling@ltu.se (Stefan Golling )
} 


\section{Introduction}

The increasing demand for lighter car structures leads manufacturers to use lighter or tougher material with equal properties in crashworthiness and durability. In recent years the use of ultra high strength steel (UHSS) has increased among leading car manufacturers. Characteristic for these steels is their good formability and hardenability. UHS steels like $22 \mathrm{MnB} 5$ are mainly used in crash impact relevant parts of the car structure. The hot stamping process can be used to tailor material properties in a single component. Production of so-called tailored properties components involves the austenitization of the blank and different cooling rates to achieve local different material properties. A variation of cooling rates is obtained by sequentially heating or cooling sections of the tool. Due to varied cooling rates different microstructures form, rapid cooling i.e. quenching causes the formation of martensite, low cooling rates promote the formation of softer phases like bainite or ferrite. In transition zones intermediate grades or mixed microstructures are formed. Karbasian and Tekkaya (2010) show the application of tailored material properties on a B-pillar where intrusion control and energy absorption is eminent. George et al. (2012) developed a tool for the production of laboratory-scale B-pillars. Hardness measurements across the transition zone between heated and cooled section revealed a width of about $10 \mathrm{~mm}$ with a varying microstructure. Further experimental work on blanks with tailored properties was conducted by Tang et al. (2014) with similar results for the width of the transition zone. Åkerström and Oldenburg (2006) showed that the phase composition in a heat treated blank can be predicted using an austenite decomposition model. This model has become a standard tool, available in the commercially available finite element code LS-Dyna, in the development of components with tailored material properties. Besides the prediction of the phase composition this model incorporates an estimation of the mechanical response of the formed composite based on the iso-strain assumption.

Homogenization methods are widely used if a material consists of two or more constituents, phases or materials which exhibit different mechanical properties. The aim of the homogenization for alloys is the estimation of the macroscopic response depending on properties of phases or constituents.

Two phenomenological models are the iso-strain and the iso-work assumptions. For the iso-strain model it is assumed that all present phases are subjected to the same strain. Bouaziz and Buessler (2002) proposed the iso-work assumption. In this method the work increment is assumed to be equal in every phase. The model is verified in its predictive capability for a composite of ferrite and pearlite and an alloy consisting of iron and silver. The described phenomenological models use a linear mixture rule for stress and strain to obtain the composite response. In the present study the phase volume fractions are used in the mixture rule. A different approach is to use a hardness value to characterize the amount of present phases. Eller et al. (2014) present a hardness dependent constitutive model. Stresses in the described model are calculated using an iso-strain assumption in a linear mixture rule where the amount of 
present phases is defined by a Vickers hardness value. An alternative approach is presented by Bardelcik et al. (2012), here the parameters of the Voce are defined in dependence of Vickers hardness. By varying the hardness value in the model, intermediate grades can be represented.

Except for the two phenomenological models introduced, two methods based on the work of Eshelby (1957) are studied. The Eshelby solution solves the problem of a single ellipsoidal inclusion in an infinite matrix. An inclusion strain concentration tensor is used to compute the strain in the inclusion and the matrix. The interaction between phases must be taken into account if the volume fraction of inclusions exceeds a few percent. An assumption in this model is the perfect bonding between inclusion and matrix phase. Mori and Tanaka (1973) used the Eshelby solution for an ellipsoidal inhomogeneity but it includes certain effects of the inhomogeneity by taking the average strain in the matrix when all inhomogeneities are present. This is in contrast to the Eshelby solution where the average strain in the matrix is taken when none of the inhomogeneities are present.

Weng (1990) proposed an analytic model based on the afore mentioned theoretical background. To estimate the elastic constants the secant moduli are computed, therefore its name secant method. The method in its original version assumes spherical inclusions in a homogeneous matrix. The user needs to decide which phase is the matrix phase, permuting the properties of matrix and inclusion yields fairly different results. Rudiono and Tomota (1997) applied the secant method on two steels with ferritic-pearlitic and ferritic-bainitic microstructure using pure phase data from Tomota et al. (1992). Calculated and experimental results are in good agreement in this study. In both cases ferrite was seen as the matrix phase and pearlite or bainite as inclusion, respectively.

The double-inclusion (DI) method was first proposed by Hori and NematNasser (1993) and extended by Lielens (1999). This model is as well based on Eshelby's inclusion theory and Mori-Tanaka's mean-field approach but applies an interpolation function between the Mori-Tanaka model and the inverse MoriTanaka model. This homogenization method can also be employed directly as a constitutive material model in a finite element code because of the explicit nature of the algorithm. This allows evaluating the stress and strain tensors for any loading condition. The double-inclusion model is easily extended from two phases to multiple phases as the strain concentration tensor is additive for all inclusions.

The aim of the present study is the evaluation of two phenomenological and two micromechanical models in their ability to predict the elasto-plastic response of a steel depending on the volume fraction of phases formed during heat treatment. The mechanical material properties used as input to the models consist of pure phase measured data. Prediction of hardening is crucial for the correct prediction of the onset of necking and the development of a failure model for mixed microstructures. In order to compare the capabilities of the methods fourteen time-temperature histories are used to produce tensile test specimens with different phase compositions. 


\section{Theory}

This study compares four mixture rules, two phenomenological and two based on micromechanical mean-field methods. The phenomenological models are the iso-strain and the iso-work assumption, the mean-field homogenization schemes are the secant method and the double-inclusion (DI) model. Throughout the study pure phases are described by an exponential function.

$$
\sigma^{(r)}=\sigma_{y 0}^{(r)}+h^{(r)}\left(1-\exp \left(-\epsilon_{p}^{(r)} n^{(r)}\right)\right)
$$

The superscript $(r)$ is a placeholder for the phase. $\sigma_{y 0}^{(r)}$ is the initial yield strength, $\epsilon_{p}^{(r)}$ is the plastic strain and $h^{(r)}, n^{(r)}$ are parameters to describe the hardening curve of respective phase.

\subsection{Phenomenological models}

The iso-strain model assumes equal strain in each present phase and a linear mixture rule for the stresses.

$$
\epsilon_{c}=\epsilon_{0}=\epsilon_{1} \quad \sigma_{c}\left(\epsilon_{c}\right)=c_{0} \sigma_{0}\left(\epsilon_{0}\right)+c_{1} \sigma_{1}\left(\epsilon_{1}\right)
$$

In Eq. (2) $\epsilon_{c}$ and $\sigma_{c}$ are the strain and stress in the composite, $\epsilon_{0}, \epsilon_{1}$ and $\sigma_{0}$, $\sigma_{1}$ are the strain and stress in phase one and two, respectively. The variables $c_{0}$ and $c_{1}$ are the volume fractions of the phases.

The iso-strain model assumes an equal strain distribution in a material. This is true for materials consisting of phases with similar mechanical properties. For materials where mechanical properties of the phases vary a strain partition is more realistic. A more realistic approach keeps the linear volume fraction mixture law for stresses and applies the same mixture law for strains, this approach was first proposed by Tomota et al. (1976).

$$
\epsilon_{c}=c_{0} \epsilon_{1}+c_{1} \epsilon_{2} \quad \sigma_{c}\left(\epsilon_{c}\right)=c_{0} \sigma_{1}\left(\epsilon_{1}\right)+c_{1} \sigma_{2}\left(\epsilon_{2}\right)
$$

The iso-work assumption, an equi-incremental mechanical work assumption, see Eq.(4), is used to decompose the strain into components applied to the different phases. The rule of mixture Eq. (3) and a suitable description for the stress depending on the strain are used to predict the composite response.

$$
\sigma_{1} d \epsilon_{1}=\sigma_{2} d \epsilon_{2}
$$

A graphical representation of the two phenomenological models is depicted in Fig, 1 


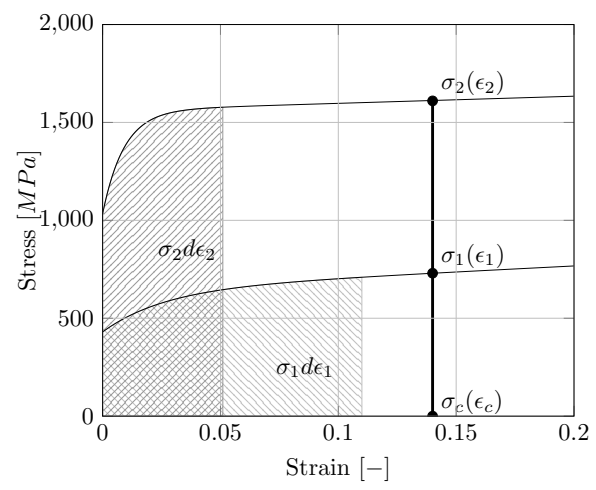

Figure 1: Schematic representation of the iso-strain and iso-work assumption.

\subsection{Models based on micromechanics}

Another group of homogenization schemes is based on continuum micromechanics. Many micromechanical methods described in literature are based on Eshelby's inclusion theory for ellipsoidal inhomogeneities.

The secant method, proposed by Weng (1990), is divided into three deformation stages. During the first stage both phases deform elastic. This stage ends if the yield criteria for one of the phases are reached. The second stage stands for elastic deformation of one phase and plastic deformation for the other, at this point it is essential to define which of the phase is the matrix and which is the inclusion. The definition of matrix and inclusion is typical for micromechanical models and clearly influences the result. The third deformation stage is reached if both phases exceed the respective yield criteria.

Depending on the volume fraction of each phase, the shape of the inclusion and the stage of deformation a strain concentration factor $b_{0}$ for the matrix and $b_{1}$ for the inclusion are calculated.

$$
b_{0}=\frac{\beta_{0}^{s}\left(\mu_{1}-\mu_{0}^{s}\right)+\mu_{0}^{s}}{\left(c_{1}+c_{0} \beta_{0}^{s}\right)\left(\mu_{1}-\mu_{0}^{s}\right)+\mu_{0}^{s}}, \quad b_{1}^{s}=\frac{\mu_{1}}{\left(c_{1}+c_{0} \beta_{0}^{s}\right)\left(\mu_{1}-\mu_{0}^{s}\right)+\mu_{0}^{s}}
$$

where $\beta$ is the shape parameter describing the shape of the inclusion and $\mu$ is the shear modulus of the matrix, subscript 1 , or the inclusion, subscript 2 , respectively. The superscript $s$ denotes that the variable is calculated using the secant modulus.

The stress in the composite depending on the plastic strain and the stage of deformation can be evaluated in an analytic way by solving a set of equations. The model is in detail described by Weng (1990), a method to incorporate a third phase is presented by Rudiono and Tomota (1997).

The double-inclusion method is as well based on Eshelby's inclusion theory and the Mori-Tanaka method and was first proposed by Hori and Nemat-Nasser 
(1993). Similar to the secant method a strain concentration tensor, $\mathbf{B}$, is calculated.

$$
\mathbf{B}=\left\{\mathbf{I}+\mathcal{E}:\left[\mathbf{D}_{0}^{-1}: \mathbf{D}_{1}-\mathbf{I}\right]\right\}^{-1}
$$

Here $\mathbf{I}$ is the fourth order identity tensor and $\mathcal{E}$ is the Eshelby tensor. The isotropic stiffness of matrix and inclusion are denoted $\mathbf{D}_{0}$ and $\mathbf{D}_{1}$, respectively. The Eshelby tensor depends on the geometry of the inclusion and its stiffness. For spheroid inclusions and isotropic stiffness it only depends on the aspect ratio of the semi axes of the inclusion and the Poisson's ratio. In the present study the elastic constants used in Eshelby's tensor are computed using the tangent moduli. Mura (1987) provides a detailed discussion on the Eshelby tensor and Eshelby's inclusion theory as well as solutions for various inclusion shapes. If in Eq. (6) the stiffness of matrix and inclusion are reversed the strain concentration tensor corresponds to an inverse Mori-Tanaka method. Using these two tensors an upper and lower bound for the macroscopic stiffness is found. Lielens (1999) proposed a material model with an interpolation between upper $\mathbf{B}_{u}$ and lower strain concentration tensor $\mathbf{B}_{l}$. This approach can be seen as strengthening effect of the real inclusion on the matrix.

$$
\mathbf{B}=\left[\left(1-\xi_{c_{1}}\right) \mathbf{B}_{l}^{-1}+\xi_{c_{1}} \mathbf{B}_{u}^{-1}\right]
$$

with the following interpolation function

$$
\xi_{\left(c_{1}\right)}=\frac{1}{2} c_{1}\left(1+c_{1}\right)
$$

This work uses the detailed discussion on computation and implementation aspects of the double-inclusion model given by Doghri and Ouaar (2003), only for the three phase composite some adaption is necessary.

For a composite with more than two phases the double-inclusion method is extended in a straight forward manner as the strain concentration tensor is additive. The upper and lower strain concentration tensors are computed for each phase. Lielens interpolation function relates each inclusion phase to the matrix phase, this implies that for every new phase taken into account an additional interpolation is used. The strain concentration tensors are then used to compute the strain in respective phase until the residual criteria of the phase is fulfilled.

In the present work the homogenization methods are studied up to the point when the Consideré criteria is fulfilled. The Consideré criteria marks the point of plastic instability or the onset of necking.

$$
\sigma=\frac{d \sigma}{d \epsilon}
$$

\subsection{Influence of carbon content on properties of martensite}

During the formation of ferrite, carbon migrates into the remaining austenite. Pure ferrite, even at elevated temperatures, can not hold considerable 
amount of carbon. The carbon migrates therefore to the remaining austenite and enriches it to a higher carbon content than the bulk material. Phases formed after ferrite thus contain higher amounts of carbon. The influence of carbon on the hardness and strength of martensite is well documented in literature. Krauss (1999) gives a review of the strengthening mechanisms associated with the various components of martensitic microstructures in steels with a carbon content up to $1.3 w t \%$.

Bainite found in high strength steels shows a similar effect on carbon partition into austenite as ferrite. Young and Bhadeshia (1994) found that most of the carbon is partitioned into the residual austenite and remains in solution rather than precipitating as carbides. In lower bainite the carbon migration is slower compared to upper bainite but even for that phase much of the carbon is nevertheless partitioned into austenite.

The carbon content in the remaining austenite before quenching is estimated by a simple mass balance. For the homogenization methods the input for the martensite hardening curve is therefore dependent on the carbon content.

Bainite shows as well a dependency of strength and hardness on carbon content though not as pronounced as martensite. During the formation of bainite, remaining austenite is enriched with carbon in a similar way than during ferrite formation but the effect is smaller as bainitic ferrite, the ferrite component in bainite, can hold more carbon.

Carbon partitioning during the formation of ferrite or bainite with the effect of increasing the amount of carbon in remaining austenite is calculated by the following relationship derived from a mass balance consideration. It is possible to use a simple mass balance as the density of the phases differs only in a negligible size.

$$
C_{\gamma}=\frac{\bar{C}-V_{f} C_{f}-V_{b} C_{b}}{1-V_{f}-V_{b}}
$$

where $C_{\gamma}$ is the carbon concentration in austenite and $\bar{C}$ is the carbon content of the bulk material. The variables $V_{f}$ and $V_{b}$ are the volume fraction of formed ferrite or bainite, $C_{f}$ and $C_{b}$ are the carbon contents of the formed ferrite and bainite. In general, $C_{f}$ is less than $0.022 w t \%$ as suggested by Chen and Cheng (1989). Bainitic ferrite contains up to $0.03 w t \%$ in solid solution found by Bhadeshia and Edmonds (1983).

The hardening curve of martensite is scaled depending on the carbon content of the remaining austenite before quenching. It is assumed that all austenite transforms into martensite. To describe the hardening Eq. (1) is used and scaling of the curve is only performed by changing the initial yield strength $\sigma_{y 0}$. Speich and Warlimont (1968), as well as Pierman et al. (2014) give a correlation between carbon content and yield strength for carbon steels. In this study the relationship proposed by Speich and Warlimont (1968) is used with the constant part adjusted to pure martensite formed from bulk material.

$$
\sigma_{y 0}=240+1720 \sqrt{C_{\gamma}}
$$


2.4. Strengthening effect of small amounts bainite in bainite-martensite composites

Tomita and Okabayashi (1983) found for microstructures consisting only of bainite and martensite a strengthening of the composite above pure martensite for bainite volume fractions up to $25 \%$. The effect behind the strengthening consists of two factors, the first is the increase of carbon in remaining austenite during bainite formation and the second is an enhancement of the bainite via a plastic constraint by the surrounding martensite. Young and Bhadeshia (1994) formulated a formula for the yield strength of bainite in a bainite-martensite composite.

$$
\sigma_{y 0}=\sigma_{y 0}^{\prime}\left(0.65 \exp \left\{-3.3 V_{b}\right\}+0.98\right)
$$

Here $\sigma_{y 0}^{\prime}$ is the yield strength of unconstrained bainite. According to the formulation above, for small volume fractions of bainite the yield strength of it is virtually equivalent to the strength of martensite with its dependency of carbon content.

\section{Experimental approach}

\subsection{Production of samples}

To compare the predictive capabilities of the homogenization methods described in Section 2, samples with different microstructures and volume fractions of phases are produced.

The tensile test specimens are cut perpendicular to rolling direction of the blank. The blank thickness is $t=1.2 \mathrm{~mm}$ and cross-section width for standard tensile test specimens is $w=12.5 \mathrm{~mm}$. A second type of test specimen has a notched geometry with a radius of $r=30 \mathrm{~mm}$ and a width of $w=15 \mathrm{~mm}$. All samples are made from the boron alloyed steel 22MnB5. The elongation during testing is measured with an extensometer with a gauge length of $L_{0}=50 \mathrm{~mm}$. The tests are performed at a constant speed of $v=0.1 \mathrm{~mm} / \mathrm{s}$. The notched specimens are additional measured using digital speckle photography (DSP). Östlund et al. (2014) describe the use of such a full field measurement to obtain stress strain curves for both types of specimens. Tensile test data in this work represent the average of two samples with different geometry. The temperature during the process is measured in three points along the gauge length using thermocouples welded on to the specimen.

Samples produced in these work possess the final specimen geometry prior to tensile testing. The chosen approach is different from most studies found in literature where usually samples are cut from formed components. Advantage of the used method is the effective use of material and the possibility of controlling the specimen temperature with good accuracy. Phase transformations in the experiment are conducted under isothermal conditions this is contradictory to the hot stamping process where continuous cooling occurs during forming operations. Simultaneous forming and cooling has as well influence on the type of formed phases and mixed microstructure present in finished components. Plastic deformation at elevated temperatures causes strain-induced ferrite formation as 


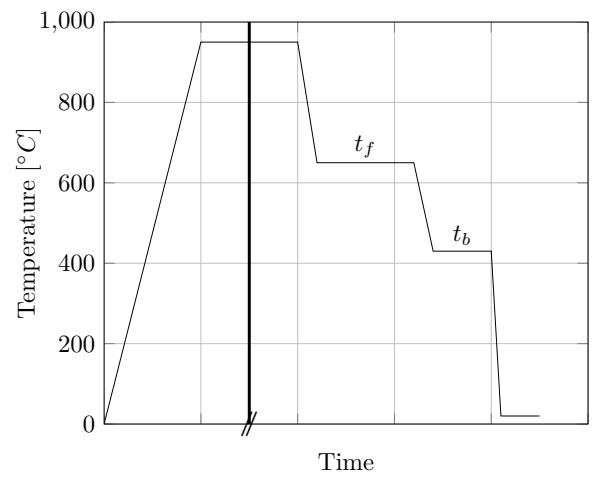

Figure 2: Schematical representation of the heat treatment used to produce different volume fractions of phases in dual- and multi-phase microstructures.

reported by Somani et al. (2001) in a study on boron alloyed bearing steel. The effect of strain induced phase transformation is incorporated into a constitutive model described by Åkerström et al. (2007) aimed for the analysis of thermomechanically formed thin sheet components. Tang et al. (2014) investigated the influence of temperature and deformation on phase transformation in a component with tailored material properties. This study emphasized the importance of the shift of TTT curves with respect to the applied stress and the effect of the deformation strain on the movement of CCT diagram. Consideration of these effects is necessary in order to obtain reasonable results in the prediction of phase transformations. During continuous cooling the formation of granular bainite is reported by Barcellona and Palmeri (2009), while isothermally formed bainite is described as upper or lower depending on transformation temperature. This discrepancy is tolerated as it does not influence the comparison between homogenization methods and present experimental results.

A tool with plane surfaces and the possibility of being heated is used for quenching to martensite and isothermal bainite transformations. The pressure on the specimen during heat treatment is $20 \mathrm{MPa}$. The tool surface has the dimension $40 \mathrm{~mm} \times 200 \mathrm{~mm}$. The temperature in the tool is measured at six points $2 \mathrm{~mm}$ below the tool surface. It is desired to get contact between upper and lower tool and both sides of the specimen at the same time, therefore spring supported holders are used. In Fig. 3 a graphical representation of the tool used in the production of samples is given.

In total fourteen phase compositions were produced. Different heat treatments are used to produce samples consisting of ferrite-martensite, ferritebainite, bainite-martensite and ferrite-bainite-martensite.

All samples are austenitized at $900{ }^{\circ} \mathrm{C}$ for $4 \mathrm{~min}$ in advance to heat treatment. Three material grades are assumed as single phases and used as input data for the models. Henceforth the single phase microstructures are labeled F730, B1015 and M1660. The material grade F730 is after austenitization inserted in the heated tool, the tool is closed until the spring supported holders are 


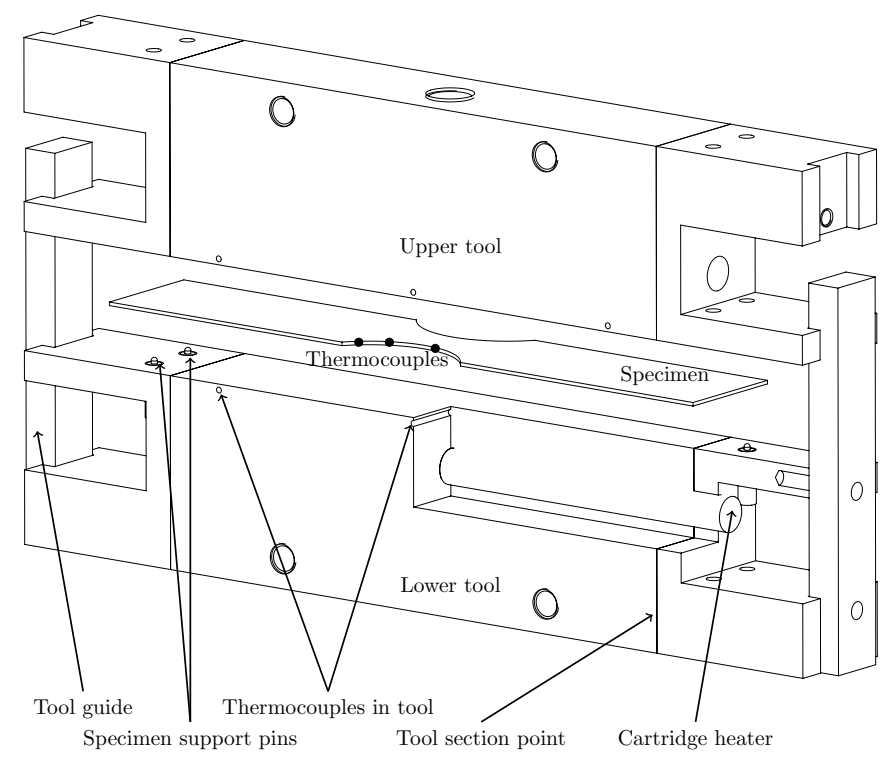

Figure 3: Representation of the tool used to obtain bainite and martensite.

in contact, post-cooling is conducted in air. The microstructure characterization shows an irregular ferritic microstructure. As reference material for bainite the material B1015 is used. The grade is produced by cooling in the tool to $430{ }^{\circ} \mathrm{C}$ and held there for $100 \mathrm{~s}$. The resulting microstructure is considered to consist of bainite. Sample M1660 is quenched in a cold tool, the microstructure of these samples is characterized to consist of martensite.

Eleven samples are produced consisting of different microstructures and volume fractions. Schematic temperature histories for the production of specimens consisting of ferrite-bainite, bainite-martensite and ferrite-bainite-martensite are shown in Fig. 22 Ferrite in these samples is formed by holding at $650{ }^{\circ} \mathrm{C}$ in an oven, bainite is formed by cooling in a tool to $430{ }^{\circ} \mathrm{C}$, holding times for both phases are shown in Table 1. To produce bainitic-martensitic microstructures the samples are after austenitization cooled in a tool heated to $430{ }^{\circ} \mathrm{C}$, different holding times are used to form varying volume fractions of bainite, see Table 1 . The remaining austenite is transformed into martensite by quenching in water.

Ferrite in samples FM-1, FM-2 and FM-3 is formed by air cooling in a tool with the blank resting on spring supported holders. Three different holding times are used to produce varying amounts of ferrite, see Table 1. The ferrite formation is stopped by quenching in a cold tool to transform the remaining austenite into martensite.

All previously described samples consist mainly of two phases. A sample containing three phases is produced using two holding temperatures, one for the ferrite and one for the bainite transformation. To form ferrite the same 
procedure as for samples FB is used but the holding time is changed. Bainite is formed isothermally in the heated tool similar to samples BM, the remaining austenite is transformed into martensite by quenching in water.

Table 1: Phase volume fraction of test samples and holding times for ferrite and bainite formation. Balance in the phase volume fraction is the amount of retained austenite.

\begin{tabular}{|c|c|c|c|c|c|}
\hline Sample & $\begin{array}{l}\text { Ferrite } \\
{[\text { vol. } \%]}\end{array}$ & $\begin{array}{l}\text { Bainite } \\
{[\text { vol.\%] }}\end{array}$ & $\begin{array}{c}\text { Martensite } \\
{[\text { vol.\%] }}\end{array}$ & $\begin{array}{c}\text { Ferrite } \\
\text { formation } \\
\text { time } t_{f}[s]\end{array}$ & $\begin{array}{c}\text { Bainite } \\
\text { formation } \\
\text { time } t_{b}[s]\end{array}$ \\
\hline F730 & 100.0 & $\mathrm{x}$ & $\mathrm{x}$ & Air cooled & 0 \\
\hline B1015 & $\mathrm{x}$ & 100.0 & $\mathrm{x}$ & 0 & 120 \\
\hline M1660 & $\mathrm{x}$ & $\mathrm{x}$ & 100.0 & 0 & 0 \\
\hline FM-1 & 38.0 & $\mathrm{x}$ & 62.0 & 20 & 0 \\
\hline FM-2 & 50.0 & $\mathrm{x}$ & 50.0 & 35 & 0 \\
\hline FM-3 & 70.0 & $\mathrm{x}$ & 30.0 & 50 & 0 \\
\hline FB-1 & 32.5 & 66.1 & 0.9 & 40 & 100 \\
\hline FB-2 & 49.0 & 48.0 & 2.6 & 60 & 100 \\
\hline FB-3 & 57.5 & 37.7 & 4.3 & 100 & 100 \\
\hline BM-1 & $\mathrm{x}$ & 22.5 & 77.4 & 0 & 8 \\
\hline BM-2 & $\mathrm{x}$ & 37.5 & 62.3 & 0 & 13 \\
\hline BM-3 & $\mathrm{x}$ & 66.2 & 33.5 & 0 & 17 \\
\hline BM-4 & $\mathrm{x}$ & 89.9 & 10.0 & 0 & 25 \\
\hline FBM-1 & 41.7 & 36.1 & 21.1 & 44 & 13 \\
\hline
\end{tabular}

\subsection{Microstructure characterization}

Besides the mechanical properties the volume fraction of phases in the mixed microstructure is needed for the models. The main characterization methods were SEM/EBSD and SEM imaging of slightly etched surfaces with subsequent image analysis. It is assumed that the volume fraction of present phases and the measured area fraction of a sample correlate. The area fractions are measured in ten points on one of the heat treated samples. The EBSD measurements are made at about one quarter of the blank thickness to avoid surface specific phenomena and center segregations. Retained austenite is distributed very finely in the microstructure and an EBSD step size of $0.05 \mu \mathrm{m}$ is used for the characterization. The remaining phases could be characterized using a larger step size of $0.2 \mu \mathrm{m}$. The samples are wet ground, polished with diamond paste to $0.25 \mu \mathrm{m}$ and subsequently polished during 20 min using an oxide suspension and water for EBSD. The final preparing step for SEM imaging is electrolytic polishing.

The estimation of phase fractions in samples FB-1, FB-2 and FB-3 is made using SEM images and manual image analysis. All samples contain small amounts of martensite and retained austenite besides the main phases bainite and ferrite. The residual austenite is distributed as small islands, both in the 
ferrite and in the martensite. Fig. $4 \mathrm{~b}$ shows an SEM picture of sample FB-1. The phase volume fractions in samples consisting of bainite and martensite are made using the same technique as for ferrite-bainite samples. The amount of residual austenite is small and is found as small islands in martensite. Fig. 4c shows a SEM picture of sample BM-3. The estimation of phase fractions in the sample consisting of three phases again uses the technique described earlier. The residual austenite was distributed as small islands in the sample. Fig. $4 \mathrm{~d}$ shows a SEM picture of the three phase sample FBM-1. The estimation of ferrite fractions in samples FM-1, FM-2 and FM-3 is made using EBSD data. Using the band slope information it is possible to separate the ferrite from the martensite. The martensite is mainly in self-tempered condition. The residual austenite is distributed as small islands and is found both in ferrite and martensite. In Tab. 1 the amount of retained austenite is given by the balance of phase volume fractions.

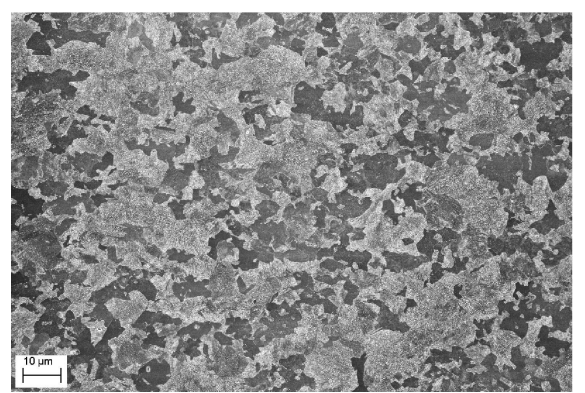

(a) Ferrite-martensite sample FM-1. Brighter areas are martensite, darker areas correspond to ferrite, area size 150 $\mu m \times 130 \mu m$ at a magnification of 2000 $\times$.

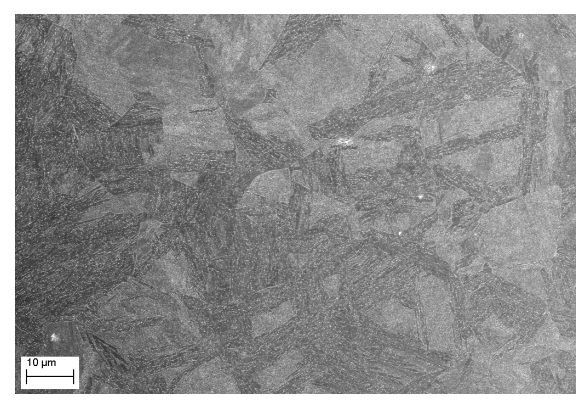

(c) Bainite-martensite sample BM-3. Brighter areas are martensite, darker areas with dot pattern correspond to bainite.

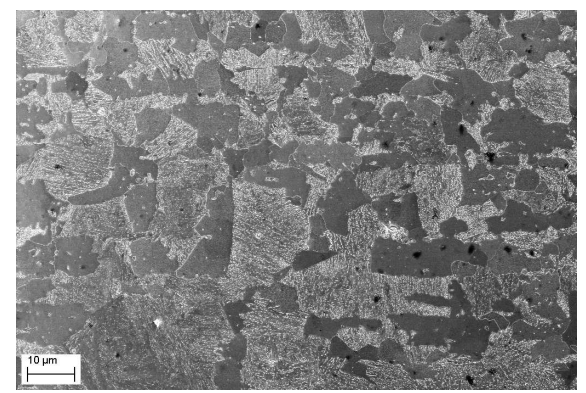

(b) Ferrit-bainite sample FB-1. Ferrite is gray colored and brighter areas are bainite. The white parts in the bainite grains is cementite.

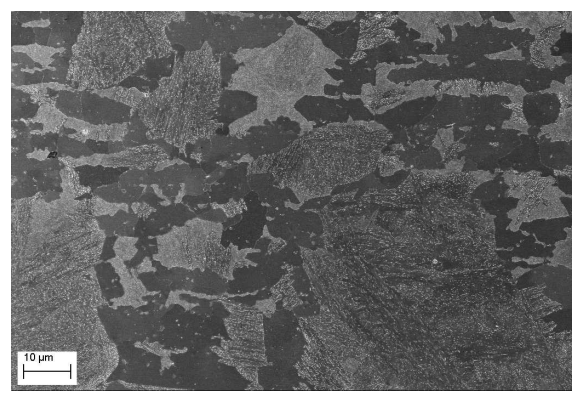

(d) Ferrit-bainite-martensite sample FBM-1. The dark gray areas are ferrite, darker areas with dot pattern are bainitic and light gray areas are martensite.

Figure 4: Examples of microstructures from scanning electron microscope. The area size is $120 \mu m \times 80 \mu m$ at a magnification of $2500 \times$ if not indicated differently. 


\section{Assumptions in modeling the mechanical response of multi-phase microstructures}

For the modeling of the hardening some assumptions are made. The secant method and the double-inclusion model need a decision which phase is the matrix phase, therefore the phase with the highest volume fraction is assumed as matrix phase. During the formation of ferrite and bainite the remaining austenite is enriched with carbon and therefore the mechanical properties of martensite change. To model the increased strength of martensite the initial yield strength is scaled, see Eq. (11). Bainite is assumed to be independent on the carbon content. Furthermore it is assumed that cementite precipitation does not make a significant contribution to the strength, but that the carbon that is rejected into the austenite makes a contribution via its effect on the solid solution strengthening of any martensite formed subsequently. Small amounts of formed phases are neglected and added to the phase with closest mechanical properties. Input data for the models are material grades F730 which is characterized as an irregular ferritic microstructure, B1015 which is a microstructure characterized as bainite isothermal transformed at $430^{\circ} \mathrm{C}$ and M1660 a fully martensitic microstructure. The Young's modulus and Poison's ratio for all phases are assumed to be equal, $200 \mathrm{GPa}$ and 0.3 respectively. The steel $22 \mathrm{MnB} 5$ used in experiment includes several alloying elements in small amounts. The only alloying element influencing results of the modeling is carbon due to its effect on martensite strength. The manufacturer specification of the carbon content is tolerated between 0.2 and $0.25 w t \%$. For the models the average value $0.225 w t \%$ is used. The initial yield strength of M1660 is not well predicted by Eq. [11), therefore the constant term is adjusted to measured observation.

\section{Results}

In total fourteen samples with different volume fraction of phases and microstructures are produced. Three samples are assumed as pure phase consisting of a single microstructure, ten samples are assumed as dual phase microstructure while one sample consists of three phases with significant volume fractions of formed phase. The models for homogenization of a mixed microstructure are in the following compared to the experimental results from tensile tests.

\subsection{Mixtures of ferrite and martensite}

Ferrite and martensite exhibit large difference in mechanical properties. During ferrite formation carbon enriches in the remaining austenite altering the initial yield strength of martensite. Experimental results showed that with increasing volume fraction of martensite the initial yield strength of the composite remains nearly unchanged. This behavior is well predicted by the secant method and the DI model but is not possible to reproduce using the phenomenological models. As a consequence the iso-strain and iso-work assumption must over predict the tensile curve for small strains. The phenomenological models cannot predict the measured composite response due to the increased strength of 
martensite. The micromechanical based models yield better results concerning the initial yield strength. The carbon strengthening of martensite contributes to the composite response only in the case of sample FM-1, in case of FM-2 and FM-3 the martensite does not reach the increased yield strength and remains elastic. See Figs. 5a $5 \mathrm{c}$ for comparison of experimental and computed results of ferrite-martensite composites.

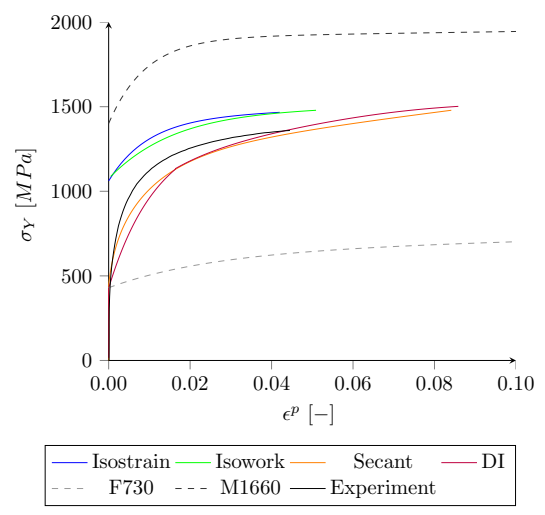

(a) Sample FM-1, 38\% ferrite and $62 \%$ martensite.

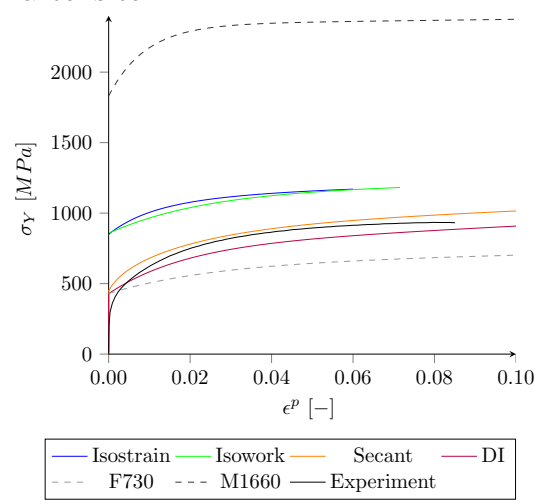

(c) Sample FM-3, 70\% ferrite and 30\% martensite.

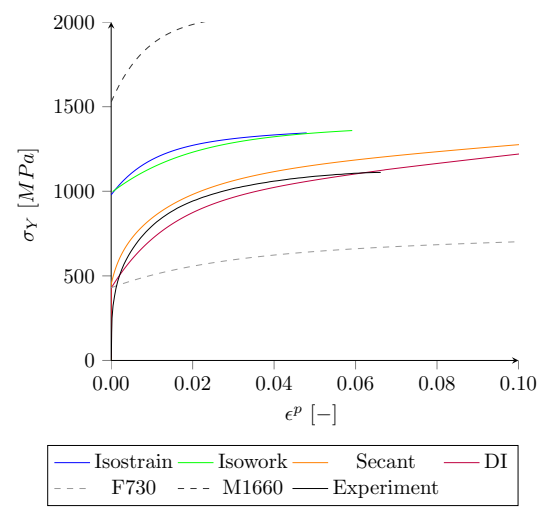

(b) Sample FM-2, $50 \%$ ferrite and $50 \%$ martensite.

Figure 5: Comparison of flow curves of samples consisting of ferrite and martensite.

\subsection{Mixtures of ferrite and bainite}

A composite made of ferrite and bainite consists of two phases with less pronounced difference in mechanical properties. The temperature at which bainite is formed is crucial for its mechanical properties. Upper bainite formed at elevated temperature has tensile properties close to ferrite-pearlite compositions. Decreasing the temperature leads to the formation of lower bainite with properties approaching the values of martensite. To test the predictive capabilities 
of the homogenization models bainite was formed at $430{ }^{\circ} \mathrm{C}$ in all composites. Experimental results show a clear influence of the bainite volume fraction on the strength of the composite. The influence of carbon content in the bainite phase on the mechanical properties is neglected. Without scaling the input data for the phases the homogenization models predict all very similar composite yield curves. The micromechanical models show throughout all compositions the lowest response for small plastic strains.

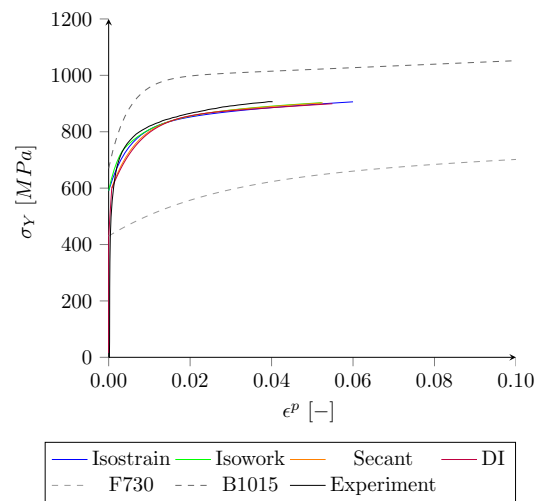

(a) Sample FB-1, 33\% ferrite and $67 \%$ bainite.

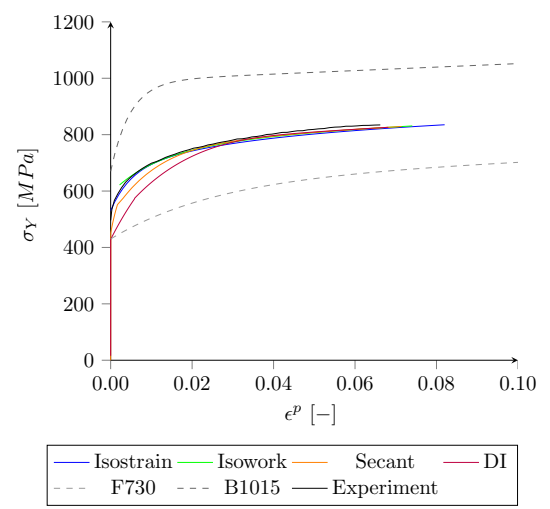

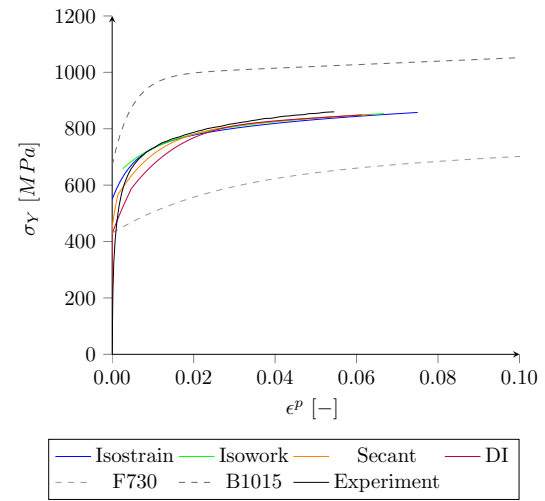

(b) Sample FB-2, $50 \%$ ferrite and 50\% bainite.

(c) Sample FB-3, $58 \%$ ferrite and $42 \%$ bainite.

Figure 6: Comparison of flow curves of samples consisting of ferrite and bainite.

\subsection{Mixtures of bainite and martensite}

Similar to the samples in the previous section, bainite and martensite show smaller difference in material behavior compared to ferrite-martensite composites. It could be expected that prediction yields good agreement but due to a strengthening effect in composites consisting of bainite and martensite modification in the calculation are necessary. 
Tomita and Okabayashi (1985) showed that microstructures consisting of bainite and martensite with a phase volume fraction of bainite up to about $25 \%$ show a strengthening behavior. Composites of these two phases exceed the properties of pure martensite formed from the bulk. The strengthening is explained in analogy with a braze joint where the brazing alloy needs to be small enough to be constrained by the surrounding phase.

Two assumptions in modeling are used to predict the response of the composites, the increase of strength of martensite with increasing carbon content and a strengthening effect of bainite due to the brazing effect. Similar to the ferritemartensite mixtures the partitioning of carbon into the remaining austenite during bainite formation influences the properties of formed martensite.

For low amounts of formed bainite all models predict similar composite response but the experimental value is not reached. Certainly, the effect of carbon enriched martensite and the bainite strengthening effect are to small to predict the measured result. For higher amounts of bainite the models show different responses. With increasing amounts of bainite the micromechanical based models predict lower stress than the phenomenological assumptions. This is explained by the martensite not entering plastic deformation for higher amounts of bainite. 


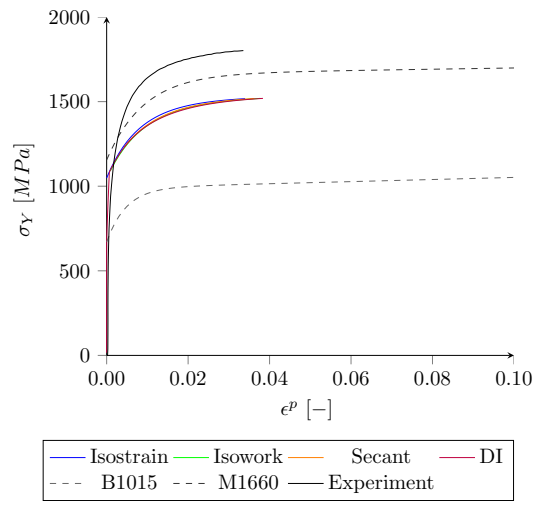

(a) Sample BM-1, 23\% bainite and $77 \%$ martensite.

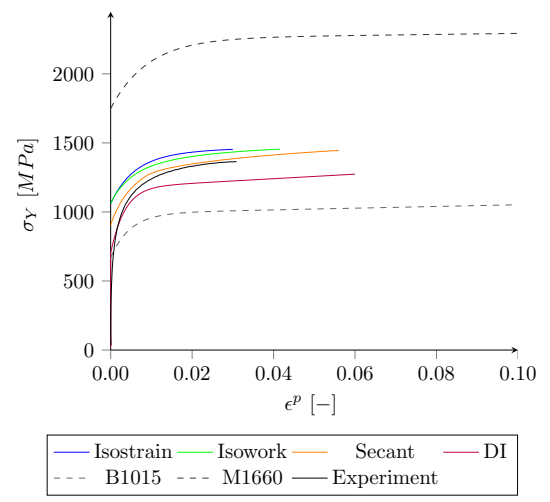

(c) Sample BM-3, $66 \%$ bainite and $34 \%$ martensite.

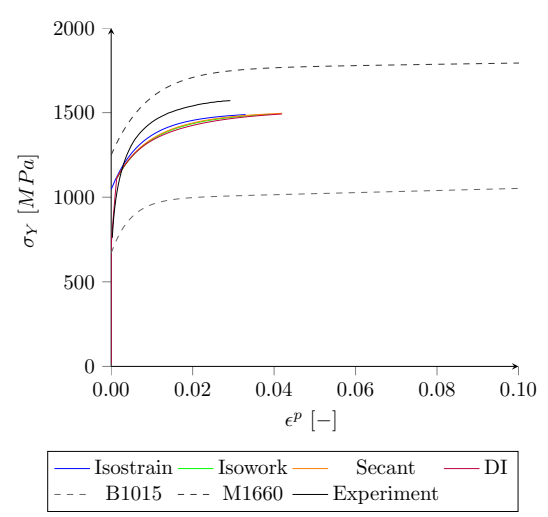

(b) Sample BM-2, $38 \%$ bainite and $62 \%$ martensite.

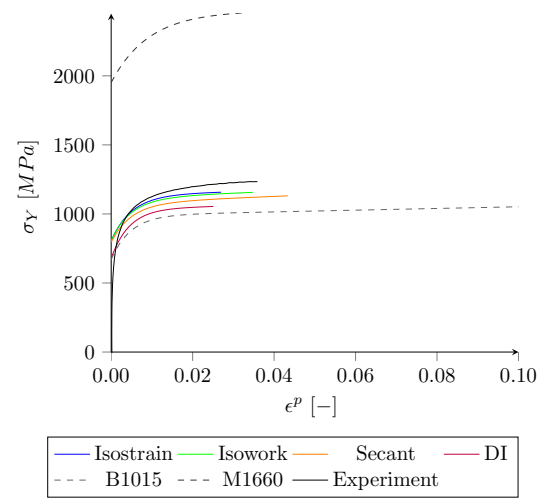

(d) Sample BM-4, $90 \%$ bainite and $10 \%$ martensite.

Figure 7: Comparison of flow curves of samples consisting of bainite and martensite.

\subsection{Mixture of ferrite, bainite and martensite}

In previous sections only two phase composites were taken into account but during heat treatment of blanks or in transition zones it is more likely that three or more phases form. The iso-strain and iso-work method are straight forward in handling three phases. Using Mori-Tanaka type estimates is as well straight forward for three phase systems while Lielens interpolation function needs some adjustments as described in Section 2. The secant method is not adapted for three phases; therefore, an iterative procedure in two steps is necessary. Several different combinations are possible for the secant method. Rudiono and Tomota (1997) performed a study on different approaches to combine three phases into a imaginary matrix or inclusion to determine the three phase composite in a second step. For the present composite ferrite was the matrix as it has the highest volume fraction and is the first formed phase, the first inclusion is bainite and the second martensite. Ferrite and bainite form an imaginary matrix in which 
martensite is embedded. This approach is in analogy with the recommendation given by Rudiono and Tomota (1997). In Fig. 8 a comparison to experimental results is shown.

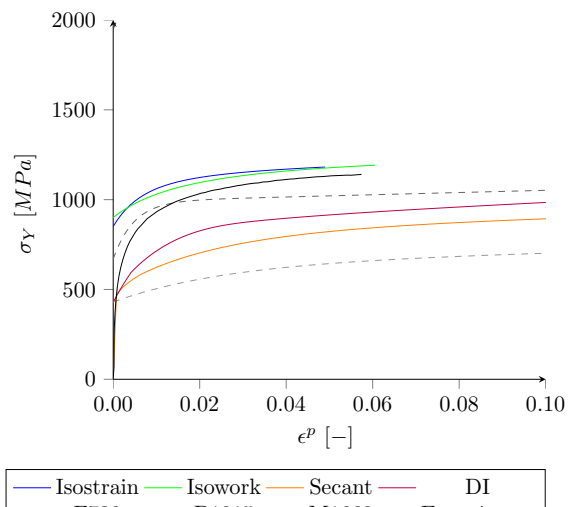

Figure 8: Flow curves of sample FBM-1, $42 \%$ ferrite, $36 \%$ bainite and $22 \%$ martensite.

The two phenomenological models show comparable results with an over prediction compared to the experimental result. The micromechanical models underestimate the experimental result. For both micromechanical based models better estimations of the composite are possible but would not be consistent with the modeling approach used for dual phase samples. The DI model yields best result if Lielens interpolation function is excluded and a pure Mori-Tanaka estimate is used. Computing an imaginary matrix with ferrite as matrix and bainite as inclusion and inserting the resultant material as inclusion into a martensite matrix yields best result for the secant method. This suggests that a small volume fraction of martensite keeps the first formed phases together. In this case martensite should be the continuous phase but this was contradictory to SEM observation of the sample.

\section{Discussion and conclusions}

Eleven samples with different microstructure compositions and volume fractions of formed phases are compared to four homogenization methods. Two homogenization methods are phenomenological, iso-strain and iso-work, and two models are based on Eshelby's inclusion theory, secant and double-inclusion (DI). The pure phases taken into consideration are ferrite, bainite and martensite. Austenite which did not transform is found in marginal amounts and is therefore neglected as a pure phase, its volume fraction in the composite is added to the softest phase present. Pearlite is not observed in any sample and is therefore not taken into consideration. For all models and compositions the same boundary conditions are applied. For samples consisting of ferrite and martensite the micromechanical based models yield the closest approximation to 
experimental results. The DI model takes in this case advantage of the strengthening effect given by the interpolation between MT- and inverse MT-scheme, while the secant method is elevated to higher results due to the martensite strengthening. For the ferrite-bainite samples all models gave results in good agreement with experimental observations. Ferrite and bainite exhibit less pronounced difference in strength resulting in a smaller sensitivity for phase volume fractions. The absence of additional strengthening terms lead to similar results for all models. For composites made of bainite and martensite a strengthening of the bainite phase is assumed while the strength of the martensite increases due to carbon partitioning. In general numerical results underpredict observations. For small volume fractions of bainite a strengthening effect is described in literature, the strengthening term is not calibrated to present results leading to less underestimated results. The use of a strengthening term in the computation of this type of microstructure is beneficial but further investigation is needed. The sample consisting of three phases uses the same modeling assumptions as the previous discussed samples. The secant method and the DI model allow different combinations of matrix and inclusion phase. Consistent with dual phase samples the phase with largest volume fractions is assumed to be the matrix. Both micromechanical models underpredict the experimental result by far, phenomenological models do not predict the initial yield strength properly but are in good agreement for larger strains. Depending on the composition, the agreement with experimental results varies between models. An advantage of the micromechanical models becomes obvious looking at the initial yield strength of the composites consisting of two different microstructures; neither the iso-strain nor the iso-work assumption is able to predict the nearly constant initial yield stress of these mixtures. This is not unexpected as both models use the same linear mixture rule. Main difference between those models is the strain distribution among the phases. The prediction of the individual strain in each phase is assumed to be important in future developments of damage criteria. To predict the onset of necking the Consideré criteria is valid in uniaxial tension. The calculation of homogenization models and likewise the experimental data is plotted until the criteria are fulfilled. Experimental results for ferrite-martensite mixtures show a brittle fracture behavior and thus the Consideré criteria marked the actual fracture with good agreement. Brittle fracture of ferrite-martensite samples is reported in literature, especially for composites with higher carbon content in martensite. Samples with less pronounced differences between phase properties, including the microstructure consisting of three phases, showed a more ductile response in tensile loading. Within this work experimental results are not displayed in Figs. $5 \mathrm{a} / 8$ beyond the onset of necking. An issue to be addressed is the microstructural characterization of the samples and their phase volume fractions. The analysis is performed in through thickness direction at half of the width of the specimen, this is done to avoid edge specific phenomena. Variation in the phase volume fractions found in this small section shows that the only parameter possible to change in the model, the phase volume fraction, undergoes an uncertainty. Advantage of the phenomenological models is their simplicity, with the iso-work assumption adding the possibility of dividing the 
strain into present phases. Drawback is the often poor prediction of composites especially for small strains. The secant method showed good results for many composites but its stepwise calculation for three phase composites is a disadvantage in further FEM implementations. The DI model is, due to its incremental nature, possible to implement into a user defined material routine in FEM codes.

\section{Acknowledgments}

Economic support for this work is supplied by VINNOVA through the project FFI OPTUS2 nr 2009-04597 which is gratefully acknowledged. The authors wish to acknowledge the supply of blanks by Gestamp Hardtech Luleå. The assistance of Swerea Kimab with microstructure characterization is appreciated. Also the support with experiment design and execution by Mr Hans Åhlin and Mr Jan Granström is acknowledged.

\section{References}

Åkerström, P., Bergman, G., Oldenburg, M., 2007. Numerical implementation of a constitutive model for simulation of hot stamping. Model. Simul. Mater. Sci. Eng. 15, 105.

Åkerström, P., Oldenburg, M., 2006. Austenite decomposition during press hardening of a boron steel - Computer simulation and test. Mater. Process. Technol. 174, $399-406$.

Barcellona, A., Palmeri, D., 2009. Effect of plastic hot deformation on the hardness and continuous cooling transformations of 22MnB5 microalloyed boron steel. Metall. Mater. Trans. A 40, 1160-1174.

Bardelcik, A., Worswick, M.J., Winkler, S., Wells, M.A., 2012. A strain rate sensitive constitutive model for quenched boron steel with tailored properties. Int. J. Impact Eng. 50, $49-62$.

Bhadeshia, H.K.D.H., Edmonds, D.V., 1983. Bainite in silicon steels: new composition-property approach Part 1. Met. Sci. 17, 411-419.

Bouaziz, O., Buessler, P., 2002. Mechanical behaviour of multiphase materials : an intermediate mixture law without fitting parameter. Rev. Métall. 99, $71-77$.

Chen, H.C., Cheng, G.H., 1989. Effect of martensite strength on the tensile strength of dual phase steels. J. Mater. Sci. 24, 1991-1994.

Doghri, I., Ouaar, A., 2003. Homogenization of two-phase elasto-plastic composite materials and structures: Study of tangent operators, cyclic plasticity and numerical algorithms. Int. J. Solids Struct. 40, $1681-1712$. 
Eller, T.K., Greve, L., Andres, M.T., Medricky, M., Hatscher, A., Meinders, V.T., van den Boogaard, A.H., 2014. Plasticity and fracture modeling of quench-hardenable boron steel with tailored properties. J. Mater. Process. Technol. 214, 1211 - 1227.

Eshelby, J.D., 1957. The determination of the elastic field of an ellipsoidal inclusion, and related problems. Proc. R. Soc. Lond. Ser. A: Math. Phys. Sci. $241,376-396$.

George, R., Bardelcik, A., Worswick, M.J., 2012. Hot forming of boron steels using heated and cooled tooling for tailored properties. J. Mater. Process. Technol. 212, 2386-2399.

Hori, M., Nemat-Nasser, S., 1993. Double-inclusion model and overall moduli of multi-phase composites. Mech. Mater. 14, 189 - 206.

Karbasian, H., Tekkaya, A.E., 2010. A review on hot stamping. J. Mater. Process. Technol. 210, 2103-2118.

Krauss, G., 1999. Martensite in steel: strength and structure. Mater. Sci. Eng. A $273275,40-57$.

Lielens, G., 1999. Micro-Macro Modeling of Structured Materials. Ph.D. thesis. UCL/FSA; Louvain-la-Neuve, Belgium.

Mori, T., Tanaka, K., 1973. Average stress in matrix and average elastic energy of materials with misfitting inclusions. Acta Metall 21, $571-574$.

Mura, T., 1987. Micromechanics of Defects in Solids. Nijhoff, Dordrecht. 2nd rev. ed. edition.

Östlund, R., Oldenburg, M., Häggblad, H.Å., Berglund, D., 2014. Evaluation of localization and failure of boron alloyed steels with different microstructure compositions. J. Mater. Process. Technol. 214, $592-598$.

Pierman, A.P., Bouaziz, O., Pardoen, T., Jacques, P.J., Brassart, L., 2014. The influence of microstructure and composition on the plastic behaviour of dual-phase steels. Acta Mater. 73, 298 - 311.

Rudiono, Tomota, Y., 1997. Application of the secant method to prediction of flow curves in multi-microstructure steels. Acta Mater. 45, 1923 - 1929.

Somani, M.C., Karjalainen, L.P., Oldenburg, M., Eriksson, M., 2001. Effects of plastic deformation and stresses on dilatation during martensitic transformation in a B-bearing steel. J. Mater. Sci. Technol. 17, 203-206.

Speich, G.R., Warlimont, H., 1968. Yield strength and transformation substructure of low-carbon martensite. J. Iron Steel Inst. 206. 
Tang, B.T., Wang, Q.L., Bruschi, S., Ghiotti, A., Bariani, P.F., 2014. Influence of temperature and deformation on phase transformation and vickers hardness in tailored tempering process: numerical and experimental verifications. J. Manuf. Sci. Eng. Trans. ASME 136.

Tomita, Y., Okabayashi, K., 1983. Improvement in lower temperature mechanical properties of 0.40 pct C-Ni-Cr-Mo ultrahigh strength steel with the second phase lower bainite. Metall. Trans. A 14, 485-492.

Tomita, Y., Okabayashi, K., 1985. Mechanical properties of 0.40 pct C-Ni-CrMo high strength steel having a mixed structure of martensite and bainite. Metall. Trans. A 16, 73-82.

Tomota, Y., Kuroki, K., Mori, T., Tamura, I., 1976. Tensile deformation of two-ductile-phase alloys: flow curves of $\alpha-\gamma \mathrm{Fe}-\mathrm{Cr}-\mathrm{Ni}$ alloys. Mater. Sci. Eng. $24,85-94$.

Tomota, Y., Umemoto, M., Komatsubara, N., Hiramatsu, A., Nakajima, N., Moriya, A., Watanabe, T., Nanba, S., Anan, G., Kunishige, K., Higo, Y., Miyahara, M., 1992. Prediction of mechanical properties of multi-phase steels based on stress-strain curves. ISIJ Int. 32, 343-349.

Weng, G., 1990. The overall elastoplastic stress-strain relations of dual-phase metals. J. Mech. Phys. Solids 38, $419-441$.

Young, C.H., Bhadeshia, H.K.D.H., 1994. Strength of mixtures of bainite and martensite. Mater. Sci. Technol. 10, 209-214. 